\title{
KEMAPANAN DAN DAYA SAING PAJAK GADAI ISLAM DI MALAYSIA: PERSPEKTIF PERINTIS
}

\author{
SUSTAINABILITY AND COMPETITIVENESS OF \\ ISLAMIC PAWNBROKER IN MALAYSIA: FROM THE \\ PIONEERS' PERSPECTIVE
}

\author{
AZILA ABDUL RAZAK \\ FIDLIZAN MUHAMMAD \\ MOHD YAHYA MOHD HUSSIN \\ FATIMAH SALWA ABDUL HADI \\ Faculty of Management and Economics \\ Universiti Pendidikan Sultan Idris
}

\begin{abstract}
Abstrak
Pembiayaan pajak gadai konvensional telah wujud sejak abad ke-19 lagi. Namun, praktis pemberian pinjaman daripada pajak gadai konvensional sering dikaitkan dengan penyelewengan dan mempunyai unsur eksploitasi terhadap peminjam. Sebagai alternatif, pajak gadai Islam yang pertama telah diwujudkan pada tahun 1992 iaitu Muassasah Gadaian Islam Terengganu dengan inisiatif oleh Majlis Agama Islam dan Adat Melayu Terengganu (MAIDAM). Sehingga tahun 2013, terdapat 464 buah cawangan daripada 10 institusi yang menawarkan pembiayaan pajak gadai Islam berbanding pajak gadai konvensional yang berlesen iaitu 259 buah. Tujuan kajian ini adalah untuk menganalisis persepsi tiga perintis utama pemegang pajak gadai Islam di Malaysia iaitu MAIDAM, YaPEIM dan Bank Kerjasama Rakyat Malaysia berkaitan aspek kemapanan dan daya saing produk, isu pembiayaan berfokuskan penggunaan dan kesedaran masyarakat terhadap kewujudan pajak gadai Islam. Kajian ini menggunakan kaedah kualitatif yang melibatkan temu bual separa berstruktur terhadap tiga institusi perintis pajak gadai Islam. Hasil kajian ini menunjukkan bahawa pajak gadai Islam berupaya untuk bersaing dan berkembang dengan penawaran sistem gadaian yang berkonsepkan syariah, pengenaan upah simpan yang rendah dan matlamat pembiayaan yang tidak berorientasikan keuntungan dan lebih kepada tanggungjawab sosial. Untuk kemapanan dan daya saing skim ini, peranan kerajaan juga amat penting terutamanya dalam mewujudkan satu akta pajak gadai Islam yang khusus serta mempertingkatkan lagi pemberian lesen kepada pemegang pajak gadai yang berpotensi. Aktiviti
\end{abstract}


promosi dan hebahan maklumat melalui media massa dan elektronik juga perlu dipertingkatkan bagi memberi kesedaran dan pemahaman kepada masyarakat khususnya mereka yang beragama Islam untuk memilih skim ar-Rahnu sebagai alternatif kepada pajak gadai konvensional.

Kata kunci: Pajak gadai Islam, pajak gadai konvensional, kemapanan, daya saing.

\section{Abstract}

Purpose - The purpose of this study is to analyze the perception of three Malaysian pioneers on Islamic pawnbroking in terms of their motivations for establishing the institution and the challenges faced by institutions such as the sustainability of the product, lending usage on consumption, and the awareness of the society towards the ar-rahnu financing existence.

Methodology - This study employs a qualitative method where semistructured interviews were conducted with the three Malaysian pioneers on Islamic pawnbroking such as MGIT/ ar-Rahnu MAIDAM, YaPEIM and Bank Rakyat.

Findings - Islamic pawnbroking scheme are competitive and sustainable due to the characteristics of the scheme such as the underlying principles of shariah, lower safe keeping fee, and welfare maximizing orientation. The government role is also important for the sustainability of the scheme, particularly in establishing a specific regulation for the scheme and expanding license granting to the potential Islamic pawnbrokers.

Originality/ Value - The implication of this study proved that Islamic pawnbroking is able to compete and sustain due to the underlying syariah principle with lower safe keeping fee, and non-profit orientation.

Keywords: Islamic pawnshop, conventional pawnshop, sustainability, competitiveness.

\section{Pengenalan}

Meskipun Malaysia dilihat sebagai sebuah negara yang memiliki kestabilan politik dan dapat mengekalkan momentum pertumbuhan ekonominya, namun tidak dinafikan terdapat segelintir masyarakat yang berada dalam kesempitan hidup dan kewangan. Keadaan ini disebabkan status sosioekonomi individu yang rendah dari 
aspek tahap pendidikan, tingkat pendapatan dan jenis pekerjaan yang memberi impak ke atas keupayaan isi rumah memperoleh pendapatan. Berasaskan kriteria tersebut, sukar bagi sektor kewangan formal untuk memberikan pinjaman kewangan sekiranya mereka memerlukan wang tunai segera. Status sosioekonomi individu atau isi rumah mempengaruhi keupayaan mendapatkan pembiayaan daripada sektor kewangan formal. Sehubungan itu, golongan berkenaan cenderung untuk memilih pembiayaan pajak gadai berbanding sumber pembiayaan lain misalnya pinjaman daripada keluarga, rakan, bank, pemberi pinjam wang dan lain-lain (Azila, 2011).

Pajak gadai merupakan satu sistem peminjaman wang menggunakan barang gadaian sebagai jaminan pembayaran semula pinjaman. Sistem pajak gadai ini mula dikesan kewujudannya seawal 3000 tahun yang lalu di China. Institusi kewangan tertua ini juga turut dikesan dalam sejarah ketamadunan awal Yunani dan Rom (Bhatt \& Sinnakannu, 2008). Berikutan kemunculan perniagaan pajak gadai ini pada awal pembangunan ketamadunan, ia secara tidak langsung menjadi institusi kewangan tidak formal yang banyak membantu golongan miskin dan berpendapatan rendah dalam mendapatkan sumber kewangan melalui prosedur yang cepat dan mudah. Malaysia mula diperkenalkan dengan sistem tersebut melalui pedagang China yang berhijrah ke Tanah Melayu pada zaman Kesultanan Melayu Melaka pada awal kurun ke-15 dan terus berkembang sehingga ke zaman pemerintahan Inggeris (Nur Azura \& Mohamad Shukri, 2006).

Oleh kerana peminjam pajak gadai berada dalam keadaan terdesak dan memerlukan wang tunai segera, golongan ini menjadi mangsa penyelewengan dan penindasan oleh pengusaha-pengusaha pemegang pajak gadai konvensional (Muhammad Saiful Islami, 2006). Meskipun operasi institusi pajak gadai dikawal selia oleh Kementerian Kesejahteraan Bandar, Perumahan dan Kerajaan Tempatan (KPKT) di bawah Akta Pemegang Pajak Gadai 1972, namun akta ini bertentangan dengan syariat Islam untuk seksyenseksyen tertentu dan lebih memihak kepada pengusaha pajak gadai. Antara peruntukan dalam Akta Pemegang Pajak Gadai 1972 yang jelas bercanggah dengan prinsip syariah ialah:

(i) Seksyen 17 - memperuntukkan kadar faedah yang tidak melebihi 2 peratus sebulan terhadap pinjaman.

(ii) Seksyen 23 - memperuntukkan barang gadaian akan menjadi harta pemegang pajak gadai selepas tempoh gadaian bagi pinjaman yang tidak melebihi RM200. 
Justeru itu, seiring dengan evolusi perkembangan kewangan Islam di Malaysia yang mula berkembang pada era 60 -an, sistem pajak gadai yang beroperasi sepenuhnya mengikut syariat Islam mula diperkenalkan pada tahun 1992 bagi menggantikan sistem pajak gadai konvensional. Sistem pajak gadai Islam ini dijangka bukan sahaja dapat memenuhi kehendak masyarakat Islam yang memerlukan pembiayaan pajak gadai berlandaskan syariah, bahkan juga dapat meningkatkan keuntungan pemegang pajak gadai Islam.

\section{Pernyataan Masalah}

Skim pajak Islam pertama di Malaysia telah ditubuhkan oleh Majlis Agama Islam dan Adat Melayu Terengganu (MAIDAM) yang dikenali sebagai Muassasah Gadaian Islam Terengganu (MGIT) pada 23 Januari 1992 dengan berkonsepkan ar-Rahn dan Qard alHassan (Azila, 2011). Pada 12 Mac 1992, Perbadanan Kemajuan Ikhtisad Negeri Kelantan (PKINK) pula telah menubuhkan Kedai Ar-Rahn di mana konsep upah simpan diperkenalkan buat pertama kalinya. Kedai Ar-Rahn ini merupakan syarikat atau institusi gadaian terawal di Malaysia (Selamah, Abdul Ghafar, Nur Azura, Raziah \& Zalina, 2005).

Seterusnya, Menteri Kewangan pada 21 Ogos 1993 telah mengumumkan bahawa skim ar-Rahnu akan dilaksanakan oleh Bank Kerjasama Rakyat Malaysia (Bank Rakyat) dengan kerjasama Yayasan Pembangunan Ekonomi Islam Malaysia (YaPEIM). Melalui skim ini, Bank Negara Malaysia bertindak sebagai penasihat dan menyediakan pakar di dalam bidang ini, YaPEIM bertindak sebagai pelabur dan Bank Rakyat pula menyediakan infrastrukutur bagi menjalankan transaksi gadaian Islam (Abdul Ghafar, 2004). Fasa pertama skim ar-Rahnu dilancarkan pada 21 Oktober 1993 oleh Bank Rakyat dan merupakan koperasi pertama di Malaysia yang menawarkan skim ini. Memandangkan sambutan yang menggalakkan daripada orang ramai, YaPEIM kemudiannya meneruskan fasa seterusnya melalui kerjasama dengan Bank Islam Malaysia Berhad pada November 1997 dan seterusnya dengan Bank Pertanian Malaysia (Agro Bank) pada Ogos 2002. YaPEIM sendiri turut menawarkan skim ini yang dikenali sebagai ar-Rahnu YaPEIM bermula pada 2 Oktober 2000.

Bilangan sistem pajak gadai Islam ini semakin bertambah apabila pihak RHB Bank, Bank Muamalat dan POS Malaysia turut sama menawarkan sistem ini kepada orang ramai. Sehingga tahun 2014, 
cawangan bank atau bukan bank yang menawarkan pembiayaan pajak gadai Islam telah menjangkau sebanyak 570 buah berbanding hanya 378 pemegang pajak gadai yang menawarkan pinjaman pajak gadai konvensional (Laporan KPKT, 2014). Bilangan institusi pajak gadai Islam dijangka akan meningkat dari setahun ke setahun. Antara faktor yang menyumbang kepada perkembangan yang positif ini ialah skim pembiayaan pajak gadai Islam berlandaskan syariah, bebas daripada amalan riba', gharar, proses yang telus serta penerapan nilai amanah dan adil kepada kedua-dua pihak iaitu pemegang pajak gadai dan peminjam (Asmadi, 2005; Skully, 2005).

Persoalannya, sejauh manakah pembiayaan pajak gadai Islam ini berupaya untuk bersaing dan menjadi alternatif kepada pembiayaan pajak gadai konvensional yang telah lama bertapak di Malaysia? Memandangkan kajian sebelum ini banyak memfokuskan kepada pandangan masyarakat terhadap peranan pajak gadai Islam, kajian ini akan menumpukan kepada pandangan pemegang pajak gadai Islam berkaitan sejarah dan motivasi penubuhan skim pajak gadai, prinsip-prinsip syariah yang diterapkan dalam pembiayaan pajak gadai Islam, kemapanan produk tersebut, isu pinjaman berfokuskan penggunaan serta promosi yang dirangka bagi tujuan meningkatkan kesedaran masyarakat Malaysia tentang kewujudan pembiayaan alternatif tersebut.

\section{Kajian Lepas}

Kajian-kajian lepas yang diteliti berkaitan skim ar-Rahnu tertumpu kepada empat skop iaitu prinsip syariah dalam skim ar-Rahnu, kemapanan dan daya saing institusi tersebut berbanding pesaingnya, isu pembiayaan untuk tujuan penggunaan berbanding pengeluaran dan kesedaran atau penerimaan masyarakat Islam terhadap skim pajak gadai Islam.

\section{Prinsip Syariah dalam Pajak Gadai Islam}

Kajian komprehensif figh berkaitan al-Rahnu telah dibincangkan oleh Muhammad Saiful Islami (2006). Perbincangan ini merangkumi konsep-konsep penting dalam gadaian Islam seperti hukum, syarat gadaian dan pandangan imam-imam mazhab Hanafi, Shafii, Hambali dan Maliki berkaitan dengan gadaian. Hasil penelitian fiqh ini, beliau menyimpulkan bahawa kesemua hukum gadaian adalah untuk menjaga kepentingan dan maslahah kedua-dua pihak sama 
ada peminjam atau pemegang pajak gadai dalam transaksi gadaian agar tidak berlaku kezaliman atau penindasan terhadap mana-mana pihak. Walaupun operasi pajak gadai Islam berlandaskan syariah, namun kajian oleh Asmadi (2004) mendapati bahawa masih wujud unsur-unsur riba dalam transaksi sistem gadaian Islam di Malaysia terutama dari aspek pengambilan upah simpan. Sebaliknya, Safinar (2005) mendapati bahawa sistem gadaian yang dilaksanakan oleh beberapa institusi pajak gadai Islam di Perlis menepati konsep syariah yang ditetapkan.

\section{Panduan Operasi Skim Pajak Gadai Islam}

Kajian lepas berkaitan panduan operasi skim pajak gadai Islam di Malaysia lebih bersifat konseptual. Kajian oleh Nur Azura et al. (2004) bertujuan untuk menganalisis keberkesanan Akta Pemegang Pajak Gadai 1972 dan Manual Garis Panduan ar-Rahnu setiap institusi pajak gadai Islam dalam menegakkan hak penggadai di Malaysia. Kajian mendapati Manual Garis Panduan ar-Rahnu lebih menitikberatkan hak penggadai berdasarkan ketelusan urusan gadaian yang dijalankan dalam sistem Ar-Rahnu berbanding pajak gadai konvensional. Namun begitu, setiap institusi yang menawarkan pajak gadai Islam ini merujuk kepada manual masing-masing bagi tujuan operasi mereka. Ini menyebabkan persoalan bagi masalah hak pengguna yang masih lagi perlu diketengahkan sama ada perlu kepada akta khusus untuk mengawal selia semua institusi pajak gadai Islam atau sudah cukup dengan akta sedia ada.

Kajian oleh Selamah (2013) pula melihat kepada cabaran yang dihadapi oleh skim ar-Rahnu apabila Akta Pemegang Pajak Gadai 1972 dipinda. Kajian mereka menjelaskan bahawa manual arRahnu mempunyai kelebihan tertentu berbanding Akta Pemegang Pajak Gadai 1972 (Pindaan 2003). Namun, cabaran utama yang akan dihadapi oleh skim ini kesan daripada pindaan akta tersebut adalah dari segi pertambahan bilangan pajak gadai dan peningkatan keupayaan memberi pinjam.

\section{Kemapanan dan Daya Saing Skim Pajak Gadai Islam}

Dari segi kemapanan institusi pajak gadai Islam, Nafisah, Abdul Ghafar, dan Selamah (2013) dan Azila (2011) mendapati kebanyakan pajak gadai memperoleh sumber modal daripada pinjaman dengan institusi kewangan. Kajian mereka menunjukkan bahawa kos atau 
modal bagi memulakan operasi institusi/ perniagaan pajak gadai agak tinggi iaitu mencecah RM2 juta. Selain itu, institusi pajak gadai perlu melengkapkan premis dengan infrastruktur keselamatan yang tinggi untuk menjamin keselamatan barang gadaian. Oleh sebab itu, mereka mencadangkan agar kerajaan memperuntukkan sebahagian dana kepada mereka agar perniagaan pajak gadai akan sentiasa kekal mapan dan seterusnya menarik pengusaha-pengusaha pajak gadai baharu untuk masuk ke dalam pasaran.

Asmadi (2004) pula dalam kajiannya mencadangkan agar bahagian zakat daripada golongan asnaf orang berhutang yang banyak jumlahnya kemungkinan boleh digunakan untuk membina institusi pajak gadai Islam. Dengan kaedah ini, pajak gadai dapat melaksanakan skim berkonsepkan Qard al-Hassan seperti yang dilaksanakan oleh MGIT. Nur Azura dan Mohamad Shukri (2006) mendapati bahawa MGIT yang tidak mengenakan sebarang upah simpan juga menunjukkan prestasi yang memberangsangkan dari segi jumlah peminjam, pembiayaan dan kadar penebusan bagi setiap peminjam di MGIT. Selain itu, kemapanan skim ar-Rahnu MGIT juga disebabkan peningkatan peratusan sumbangan ikhlas yang diberikan oleh peminjam iaitu daripada 78.12 peratus pada tahun 1992 kepada 93 peratus sehingga Mei 2006.

Selain daripada bantuan perolehan sumber modal daripada pihak kerajaan, kelangsungan skim ar-Rahnu juga boleh dicapai dengan memperuntukkan lebih banyak pembiayaan untuk tujuan pengeluaran yang produktif berbanding penggunaan. Dapatan kajian oleh Selamah et al. (2005), Bhatt dan Sinnakkannu (2008) dan Skully (2005) mendapati bahawa terdapat pelanggan pajak gadai meminjam dengan pajak gadai Islam untuk tujuan memulakan perniagaan kecilkecilan dan sebagai pusing ganti modal. Hal ini membuktikan bahawa pembiayaan pajak gadai Islam digunakan untuk tujuan produktif seterusnya dapat meningkatkan sosioekonomi peminjam. Namun begitu, dapatan kajian oleh Azila (2011) dan Azila, Fidlizan, Mohd Yahya, Suraini, dan Emilda (2013) menunjukkan bahawa kebanyakan peminjam masih lagi menggunakan pembiayaan tersebut untuk tujuan penggunaan berbanding tujuan pengeluaran terutamanya di zon tengah (Selangor dan Kuala Lumpur) dan zon selatan (Johor). Hal ini disebabkan oleh kos sara hidup yang tinggi terutamanya di bandar-bandar besar di mana keperluan perbelanjaan mereka melebihi pendapatan yang diperoleh. Namun, konsep kemaslahatan perlulah diambil kira dalam kes ini. Apabila keperluan domestik 
telah dipenuhi, maka individu yang meminjam boleh menyalurkan wang tersebut untuk tujuan produktif bagi meningkatkan taraf sosioekonominya.

Kajian oleh Mohd Rafi et al. (2012) pula mengkaji faktor-faktor kejayaan kritikal skim ar-Rahnu yang ditawarkan oleh koperasi. Antara faktor kejayaan kritikal yang dikenal pasti yang membolehkan kelangsungan skim ar-Rahnu di Malaysia ialah kepercayaan pelanggan, kadar upah simpan yang kompetitif, kecekapan staf, sistem dan lokasi perniagaan. Dengan adanya kelima-lima faktor ini, volum perniagaan dan kutipan jumlah upah simpan sebagai jumlah hasil kepada pemegang pajak gadai Islam akan dapat ditingkatkan. Selain itu, mereka juga berpendapat bahawa pemegang pajak gadai Islam berhak untuk memperoleh keuntungan. Namun, pulangan ke atas pelaburan (ROI) yang hendak dicapai perlulah mengutamakan pulangan sosial ke atas pelaburan. Hal ini disokong oleh Fatimah (1987) yang menegaskan bahawa sistem gadaian Islam tidak boleh bermotifkan keuntungan semata-mata tetapi mestilah berfokuskan kepada kebajikan sosial demi membantu masyarakat mendapatkan pembiayaan tanpa faedah.

\section{Kesedaran dan Penerimaan Masyarakat terhadap Skim Pajak Gadai Islam}

Kajian Muhammad Saiful Islami (2006) membincangkan tentang faktor-faktor yang mempengaruhi penerimaan pelanggan terhadap skim ar-Rahnu Bank Rakyat cawangan Alor Setar, Kedah. Dapatan kajian menunjukkan bahawa terdapat hubungan yang signifikan antara faktor-faktor pengetahuan terhadap skim ar-Rahnu, keistimewaan skim ar-Rahnu, kelemahan pajak gadai konvensional, layanan kakitangan dan khidmat pelanggan serta lokasi kedai arRahnu dengan penerimaan pelanggan terhadap skim ar-Rahnu.

Kajian Appannan dan Doris (2011) pula membincangkan tentang kesedaran orang ramai tentang skim ar-Rahnu Sungai Petani dan juga mengkaji faktor-faktor yang mempengaruhi penggunaan skim ar-Rahnu. Dapatan kajian menunjukkan tiada perbezaan tahap kesedaran antara jantina. Manakala dari segi bangsa, responden Melayu lebih mengetahui kewujudan skim pajak gadai Islam berbanding bangsa-bangsa yang lain di Malaysia.

Kajian oleh Azila et al. (2013) juga mendapati bahawa majoriti daripada mereka yang meminjam dengan pajak gadai Islam ialah bangsa Melayu berbanding hanya segelintir sahaja daripada bangsa 
Cina. Walaupun masyarakat bukan Melayu lebih selesa berurusan dengan pajak gadai konvensional, namun melalui pemerhatian pengkaji sudah timbul kesedaran dalam kalangan mereka untuk beralih kepada pajak gadai Islam disebabkan transaksi penggadaian yang lebih telus dan kos pinjam yang lebih murah.

\section{Metodologi}

Kajian ini melibatkan tiga perintis institusi pajak gadai Islam yang terdiri daripada MAIDAM, YaPEIM dan Bank Rakyat. Kajian ini berbentuk kualitatif dengan temu bual separa berstruktur dijalankan. Hal ini bertujuan melihat dari segi motivasi pelaksanaan skim pajak gadai Islam serta mengupas isu-isu penting yang berkaitan dengan operasi pajak gadai Islam di Malaysia berdasarkan perspektif ketigatiga perintis pajak gadai Islam seperti yang ditunjukkan dalam Lampiran 1.

Soalan temu bual separa berstruktur ini mengandungi 10 soalan yang dijadikan panduan semasa proses temu bual dijalankan bersama pemegang pajak gadai seperti yang ditunjukkan dalam Lampiran 2. Soalan ini dirangka berdasarkan kajian lepas dan juga berdasarkan maklumat yang diperoleh dari temu bual pegawai. Menurut Myers (2009), soalan temu bual separa berstruktur ini melibatkan penyediaan panduan soalan terlebih dahulu sebelum temu bual dijalankan. Namun begitu, penemu bual tidak perlu terikat kepada soalan tersebut sepenuhnya dan penemu bual digalakkan untuk menanyakan soalan-soalan baharu semasa temu bual dijalankan selain dapat membincangkan topik yang ingin dikaji dengan lebih mendalam.

Seperti mana yang dijelaskan di atas, tujuan temu bual terhadap pelanggan dilakukan bagi mendapatkan respons pihak pemegang pajak gadai Islam terhadap isu kemapanan produk ar-Rahnu, isu pembiayaan berfokuskan penggunaan berbanding tujuan pengeluaran dan kesedaran masyarakat Islam terhadap kewujudan pajak gadai Islam.

\section{Analisis Hasil Kajian dan Perbincangan}

Bahagian ini bertujuan untuk membincangkan hasil analisis daripada temu bual yang dijalankan dengan tiga perintis pajak gadai Islam iaitu MAIDAM, YaPEIM dan Bank Rakyat dari segi motivasi mereka 
menawarkan skim tersebut serta faktor-faktor yang mempengaruhi kemapanan sistem gadaian Islam ini di Malaysia. Antara faktor-faktor yang mempengaruhi kemapanan dan daya saing skim tersebut ialah (a) pengaplikasian prinsip-prinsip syariah dalam pajak gadai Islam; (b) jenis barang gadaian, panduan operasi dan strategi pemapanan pajak gadai Islam; (c) tujuan pembiayaan; dan (d) kesedaran dan penerimaan masyarakat Islam terhadap pajak gadai Islam.

\section{Penubuhan Skim Ar-Rahnu dan Motivasi}

Jadual 1.1 menunjukkan maklum balas daripada ketiga-tiga perintis pajak gadai Islam berkaitan sejarah penubuhan skim pajak Islam dan motivasi mereka dalam menawarkan produk tersebut. Menurut responden A, inisiatif untuk menubuhkan pajak gadai Islam telah dibincangkan dalam mesyuarat Majlis Kebangsaan Hal Ehwal Islam pada April 1983. Mesyuarat itu mencadangkan agar Majlis Agama Islam Negeri atau Bank Islam Malaysia Berhad melaksanakan pajak gadai Islam. Walau bagaimanapun, kedua-dua pihak tidak menunjukkan minat kecuali MAIDAM dan Permodalan Kelantan Berhad (PKB). Oleh sebab itu, kedua-dua institusi ini mengambil inisiatif awal untuk melancarkan pajak gadai Islam yang berkonsep Qard al-Hassan dan ar-Rahnu.

Jadual 1.1

Penubuhan Skim ar-Rahnu dan Motivasi

\begin{tabular}{|c|c|}
\hline Responden & Maklum balas \\
\hline $\mathrm{A}$ & $\begin{array}{l}\text { Penubuhan: } 23 \text { Januari } 1992 . \\
\text { Motivasi: Menyediakan alternatif kepada sistem pajak } \\
\text { gadai konvensional dan untuk memenuhi kewajipan sosial } \\
\text { pelanggan yang memerlukan. }\end{array}$ \\
\hline B & $\begin{array}{l}\text { Penubuhan: November } 2000 \text {. } \\
\text { Motivasi: Menyediakan pinjaman kredit mikro kepada } \\
\text { masyarakat dan untuk memenuhi prinsip syariah dalam } \\
\text { menyediakan pajak gadai berasaskan Islam. }\end{array}$ \\
\hline $\mathrm{C}$ & $\begin{array}{l}\text { Penubuhan: } 27 \text { Oktober } 1993 \text {. } \\
\text { Motivasi: Menyediakan sumber alternatif bagi mendapatkan } \\
\text { tunai segera dan menjadi alternatif kepada pajak gadai } \\
\text { konvensional. }\end{array}$ \\
\hline
\end{tabular}

Responden B daripada YaPEIM pula memaklumkan bahawa penubuhan pajak gadai Islam mereka yang pertama ialah pada bulan 
November, 2000 melalui koperasi YaPEIM. Motivasi penubuhan skim ar-Rahnu YaPEIM adalah bagi menyediakan pembiayaan mikro kepada masyarakat dan untuk memenuhi tuntutan syariah (www.efatwa.gov.my).

Manakala responden C pula menyatakan Bank Kerjasama Rakyat Malaysia telah melancarkan fasa pertama skim ar-Rahnu dengan kerjasama YaPEIM selepas diusulkan oleh Bank Negara Malaysia pada 27 Oktober 1993. Motivasi mereka melancarkan skim tersebut adalah bagi menyediakan sumber pembiayaan alternatif kepada mereka yang mempunyai cagaran dan menghindari masyakarat Islam daripada menggunakan pajak gadai konvensional yang berteraskan riba dan menindas peminjam.

Secara keseluruhannya, kesemua pajak gadai Islam terbabit telah beroperasi melebihi 20 tahun. Motivasi mereka melancarkan sistem pajak gadai Islam di Malaysia adalah untuk membantu masyarakat terutamanya golongan yang berpendapatan rendah yang memiliki simpanan dalam bentuk emas yang boleh dijadikan sandaran untuk mendapatkan tunai segera. Selain itu, skim ini juga dilihat sebagai alternatif pembiayaan kepada pajak gadai konvensional atau pemberi pinjam wang (ah-long) yang tidak berlandaskan kepada prinsipprinsip syariah serta mengeksploitasi masyarakat dengan mengenakan kadar faedah yang sangat tinggi iaitu melebihi dua peratus. Oleh itu, motivasi utama penawaran skim ini adalah untuk memenuhi keperluan tanggungjawab sosial institusi terhadap golongan yang berpendapatan rendah. Bahagian berikut menerangkan beberapa prinsip syariah yang diterapkan dalam sistem gadaian Islam ketigatiga institusi yang dipilih.

\section{Kemapanan dan Daya Saing Pajak Gadai Islam}

\section{Pengaplikasian prinsip-prinsip syariah dalam pajak gadai Islam}

Jadual 1.2 menunjukkan maklum balas perintis terhadap prinsip asas syariah yang diteraskan dalam skim pajak gadai Islam serta permasalahan syariah yang diatasi dalam sistem gadaian Islam ini.

Berdasarkan temu bual yang dijalankan dengan responden A, MAIDAM telah diberi amanah untuk mengelola MGIT. Matlamat penubuhan institusi ini ialah menawarkan pinjaman bercagar tanpa faedah atau berkonsep Qard al-Hassan kepada mereka yang memerlukan bantuan kewangan. Sehubungan itu, pinjaman ini dapat 
menyelamatkan mereka daripada amalan riba. Selain menguruskan MGIT, MAIDAM turut menubuhkan Muassasah ar-Rahnu. Namun, sistem gadaian Islam ini adalah berlandaskan konsep upah simpan seperti yang diamalkan oleh skim pajak gadai Islam YaPEIM dan Bank Rakyat susulan kekangan dana Qard al-Hassan yang dimiliki oleh MGIT. Menurut kesemua responden, pembiayaan gadaian Islam yang dipraktikkan oleh mereka adalah berasaskan empat konsep iaitu: (i) ar-Rahn yang merujuk kepada barang yang berharga yang dijadikan sandaran kepada hutang; (ii) Qard al-Hassan yang merujuk kepada pinjaman tanpa faedah yang hanya memerlukan peminjam untuk membayar balik nilai yang dipinjam, namun peminjam boleh membayar saguhati (hibah) mengikut budi bicara sebagai tanda penghargaan; (iii) al-Wadiah yad Dhamannah yang merujuk kepada kontrak antara peminjam dengan pemberi pinjaman untuk tujuan keselamatan; dan (iv) al-Ujrah yang merujuk kepada caj bagi perkhidmatan yang diberikan dalam menjaga atau menyimpan barang gadaian.

Jadual 1.2

Prinsip Syariah dalam Gadaian Islam dan Masalah Syariah yang Diatasi

\begin{tabular}{|c|c|}
\hline Responden & Maklum Balas \\
\hline A & $\begin{array}{l}\text { Prinsip syariah: ar-Rahn, Qard al-Hassan dan al-Wadiah yad } \\
\text { Dhammanah. } \\
\text { Masalah-masalah yang diatasi: riba dan gharar. }\end{array}$ \\
\hline
\end{tabular}

B dan C Prinsip syariah: ar-Rahn, Qard al-Hassan, al-Wadiah yad Dhammanah dan al-Ujrah.

Masalah-masalah yang diatasi: riba dan gharar.

Kesemua responden juga bersetuju bahawa dengan pelaksanaan pajak gadai Islam dapat menghindari peminjam daripada berurusan dengan pembiayaan yang mempunyai elemen riba. Perlu diingatkan bahawa kos upah simpan yang ditetapkan ke atas barang gadaian itu dibenarkan oleh Jawatankuasa Majlis Fatwa Kebangsaan selagi ia tidak berunsur eksploitasi.

Selain daripada riba, elemen gharar juga berlaku dalam operasi pinjaman pajak gadai konvensional seperti memberi nilai yang jauh lebih rendah terhadap barang gadaian, mengeluarkan resit pajak gadai yang tidak jelas dan boleh mengelirukan peminjam, dan amalan tidak 
beretika yang lain. Menurut responden A, antara tatacara gadaian Islam yang boleh mencegah elemen gharar ialah menyenaraikan kesemua butiran peminjam termasuklah nilai barang gadaian, jumlah pinjaman, bayaran yang dikenakan, tempoh penebusan, dan lain-lain terma dan syarat pinjaman di dalam resit gadaian agar tidak timbul sebarang keraguan atau manipulasi dalam proses membuat pinjaman. Oleh sebab itu, melalui pajak gadai berasaskan syariah, kesemua responden bersetuju bahawa penerapan amalan-amalan beretika seperti jujur, boleh percaya, telus, berpengetahuan, dan adil akan dapat mencegah isu-isu eksploitasi dan manipulasi terhadap para peminjam khususnya terhadap golongan berpendapatan rendah. Hal ini sekaligus akan dapat meningkatkan daya saing pajak gadai Islam sebagai salah satu sumber pinjaman mikro kepada mereka yang memerlukan pinjaman tunai segera.

\section{Jenis barang gadaian, panduan operasi dan strategi pemapanan}

Jadual 1.3 menunjukkan dapatan temu bual dengan tiga wakil perintis sistem gadaian Islam di Malaysia berkaitan dengan jenis barang gadaian yang diterima, akta yang digunapakai dan kemapanan atau daya saing pajak gadai Islam terhadap pesaingnya.

Kajian mendapati bahawa kesemua institusi tersebut hanya menerima emas jenis 18K - 24K. Bagi meningkatkan daya saing pajak gadai Islam dengan pesaingnya, beberapa cadangan dan penambahbaikan polisi telah dilaksanakan oleh ketiga-tiga perintis yang terlibat. Sebagai contoh, Bank Rakyat telah menerima jongkong emas sebagai cagaran. MAIDAM pula masih meneroka mekanisme mempelbagaikan penerimaan barang gadaian misalnya menggunakan unit amanah. Walau bagaimanapun, terdapat keperluan untuk berbincang dengan institusi unit amanah mengenai keselamatan dana amanah tersebut. Sebelum ini, MAIDAM juga menerima emas putih sebagai cagaran. Walau bagaimanapun, masalah timbul apabila peminjam tidak menuntut barang gadaian tersebut menyebabkan sukar bagi MAIDAM menjualnya bagi mengurangkan kerugian.

Sebagai alternatif, YaPEIM mengambil percubaan pertama menerima berlian sebagai cagaran bersama dengan emas. Menurut responden $\mathrm{B}$, usaha ini bertujuan untuk memberi lebih nilai kepada pelanggan. Sehubungan itu, YaPEIM telah menghantar kakitangan mereka ke Institut Gemologi Paramita di Jakarta, Indonesia untuk meningkatkan kepakaran mereka dalam penggredan berlian. 
Jadual 1.3

Jenis Barang Gadaian, Panduan Operasi dan Strategi Pemapanan Pajak Gadai Islam

\begin{tabular}{cl}
\hline Responden & \multicolumn{2}{c}{ Maklum Balas } \\
\hline A & Barang gadaian: Emas \\
& Panduan operasi: Akta Pemegang Pajak Gadai 1972 dan \\
& Manual Prosedur Skim ar-Rahnu MAIDAM 2006. \\
& Strategi pemapanan: Memberi penekanan kepada \\
& volum/jumlah pelanggan dan caj bayaran rendah serta \\
& menggalakkan pemberian lesen kepada bakal pemegang \\
& pajak gadai Islam baharu.
\end{tabular}

B Barang gadaian: Emas dan berlian.

Panduan operasi: Manual Garis Panduan ar-Rahnu YaPEIM. Strategi pemapanan: Setiap operator ar-Rahnu mempunyai kadar upah kompetitif. Hanya operator yang mempunyai sumber kewangan yang kukuh dan besar serta mampu mengurangkan kos operasi sahaja boleh mengenakan upah yang minima.

C Barang gadaian: Emas

Panduan operasi: Garis Panduan Operasi Pajak Gadai-i.

Strategi pemapanan: Penawaran skim ar-Rahnu oleh bankbank perdagangan dapat kurangkan kos operasi bank.

Walaupun terdapat perbincangan dalam kalangan semua institusi pajak gadai Islam berkaitan isu mewujudkan peraturan piawai untuk skim ar-Rahnu, namun setakat ini tidak ada satu garis panduan khusus yang digubal bagi operasi pajak gadai Islam selain daripada Akta Pemegang Pajak Gadai 1972. Berdasarkan temu bual yang dijalankan, institusi seperti YaPEIM dan Bank Rakyat tidak terikat dengan Akta Pemegang Pajak Gadai 1972 seperti yang dinyatakan dalam Seksyen 46, kecuali skim ar-Rahnu oleh MGIT. Umumnya, operasi institusi dilaksanakan berdasarkan garis panduan ar-Rahnu masing-masing. Menurut responden $B$, walaupun garis panduan yang dirujuk oleh setiap institusi berbeza, namun terma kandungan kontrak adalah hampir sama; hanya berbeza dari segi margin pinjaman dan upah simpan yang dikenakan.

Dari segi kemapanan sistem pajak gadai Islam, kesemua responden bersetuju bahawa prospek pembiayaan pajak gadai Islam di Malaysia sebagai alternatif kepada pajak gadai konvensional 
adalah memberangsangkan. Menurut responden A, penawaran pembiayaan gadaian Islam ini merupakan fardu kifayah dan tidak berorientasikan keuntungan semata-mata. Oleh sebab itu, MAIDAM memberi fokus kepada strategi yang efektif dalam meningkatkan bilangan pelanggan. Mereka berpendapat bahawa sekiranya upah simpan yang dikenakan adalah rendah, ia memberi kesan kepada peningkatan jumlah pelanggan, dan sebaliknya pula sekiranya upah simpan adalah tinggi. Oleh itu, dengan pinjaman tanpa faedah melalui MGIT dan pengenaan kos upah simpan yang paling minimum oleh Muassasah ar-Rahnu MAIDAM, objektif utama MAIDAM iaitu menawarkan pembiayaan ini untuk pembangunan sosioekonomi masyarakat setempat dapat direalisasikan.

Menurut responden B pula, kemapanan institusi pajak gadai Islam dapat dikekalkan disebabkan pinjaman pajak gadai adalah sejenis pinjaman yang boleh mengurangkan risiko ketidakpatuhan menebus barang gadaian oleh peminjam. Pada masa ini, walaupun persaingan antara institusi ar-Rahnu dan pajak gadai konvensional dalam menyediakan pinjaman kepada pelanggan tidak dapat dielakkan, YaPEIM sangat optimis bahawa skim ar-Rahnu mampu menjadi alternatif kepada perniagaan pajak gadai konvensional di masa hadapan. Mereka percaya bahawa dengan menyediakan staf penilai yang kompeten, jaminan keselamatan barang gadaian yang tinggi, dan kadar upah simpan yang rendah akan meningkatkan kepercayaan dan kecenderungan masyarakat meminjam dengan institusi pajak gadai Islam. Selain itu, dengan pengenaan kadar upah yang minimum akan meningkatkan permintaan terhadap skim ar-Rahnu YaPEIM seterusnya mengekalkan kemapanan skim tersebut.

Responden C pula berpendapat institusi pajak gadai Islam dapat dikekalkan dalam jangka panjang disebabkan pembiayaan ini adalah berlandaskan prinsip-prinsip syariah dan kejujuran (dari segi penjagaan aset pelanggan) dan ketelusan (dari segi menilai cagaran berdasarkan harga semasa) berbanding dengan pajak gadai konvensional. Dengan wujudnya bank-bank perdagangan yang menawarkan skim pajak gadai Islam, adalah dijangka bahawa ia boleh menghapuskan stigma negatif masyarakat terhadap institusi pajak gadai sebelum ini, seterusnya menarik lebih ramai pelanggan, bukan sahaja yang beragama Islam malahan juga kepada yang bukan beragama Islam untuk berurusan dengan mereka. Malah katanya, skim ar-Rahnu tidak harus dilihat sebagai sumber 
pembiayaan kepada mereka yang berpendapatan rendah, malahan juga kepada seluruh strata masyarakat di Malaysia yang memerlukan pinjaman wang segera. Tambahan lagi, bank-bank perdagangan digalakkan untuk menawarkan skim tersebut. Ini kerana sekiranya bank mengendalikan skim ar-Rahnu, kos operasi akan dapat dikurangkan berbanding dengan membuka kedai ar-Rahnu secara persendirian.

Kesemua responden bersetuju bahawa peranan kerajaan amatlah penting untuk memastikan perniagaan pajak gadai Islam berdaya saing dan mapan dalam jangka panjang. Bagi responden $\mathrm{A}$, isu pemberian lesen juga perlu diberi tumpuan dan disemak semula oleh kerajaan. Sebagai contoh, pihak MAIDAM sebelum ini berhadapan kesukaran dalam memperoleh lesen daripada pihak KPKT bagi membuka cawangan baru kerana beberapa keperluan yang perlu dipenuhi serta halangan politik. Bagi mengatasi halangan ini, MAIDAM telah mewujudkan koperasi MAIDAM serta menjalankan usaha sama dengan koperasi yang lain bagi menawarkan skim pajak gadai Islam. Rentetan itu, operasi MAIDAM telah berjalan dengan lancar dan memberi pinjaman dengan lebih berkesan.

Kekangan yang dihadapi oleh MAIDAM adalah berlawanan dengan Bank Rakyat. Menurut responden C, Bank Rakyat tidak menghadapi sebarang masalah mendapatkan modal untuk memberi pinjaman kepada pelanggan. Sehingga kini, Bank Rakyat telah memperluaskan skim ar-Rahn dengan menawarkan skim az-Zahab yang membolehkan peminjam mendapatkan jumlah pinjaman yang lebih besar iaitu dari RM10,001.00 hingga RM100,000.00 dengan metode pembayaran balik pinjaman yang mudah dan pengenaan upah simpan yang rendah.

\section{Tujuan pembiayaan}

Tujuan pinjaman dibuat oleh peminjam pajak gadai juga mempengaruhi kemapanan sistem gadaian Islam. Berdasarkan kepada Jadual 1.4, kesemua responden bersetuju bahawa maslahah pelanggan (kepentingan awam) adalah lebih utama daripada mempertikaikan mengenai tujuan meminjam sama ada untuk penggunaan atau pengeluaran yang bersifat produktif. 
Jadual 1.4

Tujuan Penggunaan berbanding Tujuan Pengeluaran

\begin{tabular}{|c|c|}
\hline Responden & Maklum Balas \\
\hline $\mathrm{A}$ & $\begin{array}{l}\text { Konsep maslahah terhadap peminjam perlu dipertimbangkan } \\
\text { dalam memahami penggunaan pinjaman yang diberikan } \\
\text { tanpa mengambil kira tujuan mereka meminjam dengan } \\
\text { pajak gadai. }\end{array}$ \\
\hline B & $\begin{array}{l}\text { Walaupun kedua-dua tujuan ini memberi impak yang berbeza } \\
\text { kepada ekonomi, namun objektif utama YaPEIM adalah } \\
\text { untuk membantu mereka khasnya golongan berpendapatan } \\
\text { rendah dan masyarakat yang 'dipinggirkan' oleh institusi } \\
\text { kewangan formal. }\end{array}$ \\
\hline $\mathrm{C}$ & $\begin{array}{l}\text { Walaupun dari perspektif ekonomi, pinjaman untuk } \\
\text { tujuan pengeluaran boleh menjana pendapatan pelanggan } \\
\text { berbanding dengan tujuan penggunaan; kita masih } \\
\text { perlu mengambil kira maslahah pelanggan jika mereka } \\
\text { menggunakannya untuk tujuan penggunaan. }\end{array}$ \\
\hline
\end{tabular}

Berdasarkan kajian tidak rasmi yang dilakukan oleh pihak MAIDAM, kebanyakan pelanggan membuat pinjaman bagi tujuan penggunaan isi rumah dan bukan tujuan produktif (perniagaan, pembelian aset dan sebagainya) pada kadar nisbah 70: 30. Responden A mengatakan sekiranya peminjam menggunakan wang pinjaman untuk tujuan penggunaan, impak positif terhadap pembiayaan pajak gadai Islam hanyalah bersifat jangka pendek sahaja. Namun, sekiranya pinjaman tersebut digunakan untuk tujuan produktif, ia memberikan kesan yang positif dalam jangka panjang di mana taraf hidup peminjam tersebut dapat ditingkatkan. Walaupun pihak MAIDAM menggalakkan peminjam meminjam untuk tujuan produktif berbanding dengan tujuan penggunaan dalam pinjaman, konsep maslahah perlu dipertimbangkan. Oleh sebab itu, pihak MAIDAM mengandaikan bahawa sekiranya keperluan domestik telah dipenuhi (misalnya membayar bil-bil utiliti dan perbelanjaan rumah), maka peminjam boleh memberi tumpuan pula kepada membuat pinjaman untuk tujuan produktif yang akan menjana pendapatan mereka dan seterusnya memperbaiki taraf sosioekonomi mereka. Menurut responden A, budaya masyarakat di Terengganu (terutamanya kaum Melayu) adalah dengan membeli emas sekiranya terdapat lebihan pendapatan bagi tujuan perniagaan atau membiayai keperluan harian. 
Dari sudut pandangan responden B dan C pula, mereka bersetuju bahawa pinjaman untuk tujuan produktif akan memberi lebih banyak nilai tambah kepada pelanggan dari segi menjana jumlah pendapatan isi rumah berbanding pinjaman untuk tujuan penggunaan. Namun, objektif utama mereka menawarkan pajak gadai Islam adalah untuk membantu mereka yang memerlukan tunai segera berasaskan syariah, terutama golongan berpendapatan rendah serta mereka yang mengalami masalah mendapatkan pembiayaan daripada bank akibat disenarai hitam dan sebagainya.

\section{Kesedaran dan penerimaan masyarakat Islam terhadap pajak gadai Islam}

Penerimaan masyarakat Islam terhadap skim ar-Rahnu yang ditawarkan juga memberi impak kepada kelangsungan skim tersebut. Jadual 1.5 menunjukkan maklum balas yang diperoleh daripada ketiga-tiga responden berkaitan kesedaran dan penerimaan masyarakat Islam terhadap pajak gadai Islam. Menurut responden A, walaupun MGIT dan Muassasah ar-Rahnu MAIDAM menawarkan upah simpan yang lebih rendah, kaunter berurusan dan ruang pejabat yang kondusif, lokasi yang strategik dan mudah diakses, namun terdapat segelintir masyarakat Islam yang masih berurusan dengan pajak gadai konvensional. Melalui pemerhatian dan temu bual tidak rasmi, faktor seperti malu, kesetiaan kepada pajak gadai konvensional, dan kurangnya prosedur dan dokumentasi yang diperlukan oleh pajak gadai konvensional menyebabkan mereka lebih cenderung berurusan dengan pajak gadai konvensional. Perkara ini juga dipersetujui oleh responden $C$ yang mendapati bahawa isu prosedur dan dokumentasi yang kurang oleh pajak gadai konvensional menyebabkan peminjam cenderung berurusan dengan mereka. Namun demikian, beliau menegaskan bahawa prosedur peminjaman pajak gadai Islam yang agak 'lambat' iaitu daripada proses penilaian barang gadaian, dokumentasi dan diakhiri oleh proses ijab dan qabul oleh kedua-dua pihak adalah bagi menjamin keadilan sosial kepada peminjam dan memastikan pinjaman tersebut berlandaskan syariah. Sesetengah daripada peminjam juga tidak dapat membezakan antara kadar faedah yang dikenakan oleh pajak gadai konvensional dan upah simpan oleh pajak gadai Islam. Bagi menjelaskan perbezaan kedua-dua kadar ini, MAIDAM telah mengarahkan kakitangan (kaunter hadapan) untuk setiap cawangan memberikan penerangan yang jelas berkaitan kedua-dua terma tersebut bagi mendidik para peminjam terutamanya yang beragama Islam tentang skim gadaian Islam. 
Jadual 1.5

Kesedaran dan Penerimaan Masyarakat Islam terhadap Kewujudan Pajak Gadai Islam

\begin{tabular}{cl}
\hline Responden & \multicolumn{1}{c}{ Maklum Balas } \\
\hline 1 & $\begin{array}{l}\text { Masih kurang kesedaran dan penerimaan dalam kalangan } \\
\text { masyarakat Islam dan bukan Islam tentang skim ini. Kaedah } \\
\text { penerangan di kaunter depan diaplikasi bagi memberikan } \\
\text { pendidikan berkaitan sistem gadaian Islam. }\end{array}$ \\
& $\begin{array}{l}\text { Terdapat segelintir masyarakat Islam masih berurusan } \\
\text { dengan pajak gadai konvensional. Aktiviti pemasaran yang }\end{array}$ \\
& $\begin{array}{l}\text { lebih aktif perlu diambil untuk menggalakkan kesedaran } \\
\text { produk ini. }\end{array}$ \\
& $\begin{array}{l}\text { Pelanggan beragama } \\
\text { perkhidmatan pajak gadai konvensional kerana beberapa } \\
\text { faktor. Manakala, pelanggan bukan Islam telah menunjukkan } \\
\text { minat mereka dalam menggunakan skim ar-rahnu terutama } \\
\text { dalam kalangan masyarakat India. Beberapa program dan } \\
\text { kempen telah dibangunkan untuk menguasai pasaran dan } \\
\text { meningkatkan kesedaran kepada masyarakat. }\end{array}$ \\
&
\end{tabular}

Responden B pula menyatakan fenomena peminjam dalam kalangan orang Islam cenderung untuk berurusan dengan pajak gadai konvensional disebabkan kurangnya kesedaran dan pengetahuan terhadap konsep riba yang diterapkan dalam pembiayaan konvensional. Selain itu, faktor kesetiaan, faktor malu berurusan dengan pajak gadai Islam, tidak memahami konsep riba dan kadar pinjaman yang ditawarkan oleh pajak gadai konvensional lebih tinggi juga menyumbang kepada kecenderungan masyarakat Islam menggunakan pajak gadai konvensional. Oleh itu, YaPEIM telah memulakan beberapa aktiviti promosi kepada masyarakat dengan membuka KIOSK di pasar raya dan di kawasan-kawasan awam yang lain, iklan melalui radio dan televisyen, menggunakan belon dan papan iklan di sepanjang lebuh raya, dan juga menubuhkan satu kempen dikenali sebagai 'Hari Bersama Pelanggan' untuk meningkatkan hubungan baik sesama pelanggan dan masyarakat serta meningkatkan tahap kefahaman masyarakat Islam terhadap konsep riba yang ditegah dalam Islam.

Kesimpulannya, kesemua institusi pajak gadai sependapat bahawa mereka bertanggungjawab mendidik dan meningkatkan kesedaran 
serta penerimaan masyarakat terhadap pinjaman segera pajak gadai Islam yang terhindar daripada unsur riba, gharar serta menerapkan konsep-konsep keadilan, ketelusan, dan kejujuran kepada kedua-dua pihak yang terlibat. Menurut kesemua responden, stigma negatif yang mengaitkan pajak gadai dengan kemiskinan perlu dihakis. Keadaan ini ditunjukkan oleh trend semasa yang menunjukkan masyarakat daripada pelbagai lapisan kaum, agama, tahap pendidikan dan pendapatan menggunakan sistem pajak gadai Islam bagi pelbagai tujuan. Realitinya, mereka yang membuat pinjaman tunai segera di institusi pajak gadai adalah mereka yang mempunyai harta untuk dicagarkan. Kaedah pembiayaan ini berbeza dengan proses pinjaman peribadi daripada institusi bank yang hanya memerlukan seseorang peminjam itu untuk mengemukakan penyata gaji dan surat pengesahan jawatan daripada majikan sebagai sandaran untuk mendapatkan pinjaman. Walhal, kedua-dua dokumen tersebut tidak dapat menggambarkan status kewangan/aset sebenar seseorang individu itu.

\section{Kesimpulan}

Kajian ini dijalankan bagi mendapatkan maklum balas dan pandangan tiga buah perintis pajak gadai Islam berkaitan kemapanan dan daya saing institusi pajak gadai Islam mendepani cabaran semasa di Malaysia. Implementasi konsep syariah yang menyeluruh, pengenaan upah simpan yang rendah, proses pinjaman yang lebih telus, cekap dan amanah serta matlamat institusi yang berorientasikan tanggungjawab sosial adalah antara kriteria utama skim ar-Rahnu dipilih sebagai pembiayaan alternatif kepada pajak gadai konvensional. Untuk memastikan kelangsungan dan daya saing sistem ini juga, sokongan daripada pihak kerajaan amatlah penting terutamanya dari aspek pemberian lesen baharu kepada pemegang pajak gadai yang berpotensi dan pembentukan akta khusus bagi pengoperasian pajak gadai Islam agar dapat membantu institusi untuk beroperasi secara lebih sistematik dan memberi keyakinan kepada pelanggan pada masa hadapan. Aktiviti promosi dan hebahan maklumat melalui media massa dan elektronik juga perlu dipertingkatkan bagi memberi kesedaran dan pemahaman kepada masyarakat khususnya mereka yang beragama Islam untuk memilih skim ar-Rahnu sebagai alternatif kepada pajak gadai konvensional. 


\section{Rujukan}

Abdul Ghafar Ismail. (2004, Oktober 12-14). Skim ar-rahnu pengukuhan kerjasama serantau: Pengalaman Malaysia. Kertas kerja dibentangkan di Konvensyen ar-Rahnu Serantau, anjuran Yayasan Pembangunan Ekonomi Islam Malaysia dengan kerjasama Sekretariat ar-Rahnu Serantau. Kuala Lumpur.

Appannan, S., \& Doris, G. (2011, Oktober 21-22). A study on Islamic pawn broking awareness and factors influencing the scheme in Sungai Petani, Kedah. Kertas kerja dibentangkan di $2^{\text {nd }}$ International Conference on Business and Economic Research 2011, anjuran International Economics Development and Research Center, Cario.

Asmadi Mohamed Naim. (2005). Sistem gadaian Islam. Islamiyyat, 26(2), 39-57.

Azila Abdul Razak, Fidlizan Muhammad, Mohd Yahya Mohd Hussin, Suraini Mohd Rhouse, \& Emilda Hashim. (2013, Jun Jun 7-9). Peranan institusi pajak gadai Islam dalam pembangunan sosioekonomi. Kertas kerja dibentangkan di Persidangan Kebangsaan Ekonomi Malaysia ke-8, anjuran Fakulti Ekonomi dan Pengurusan UKM dengan kerjasama Majlis Profesor Negara, Johor Bahru.

Azila Abdul Razak. (2011). Economic and religious significance of the Islamic and conventional pawnbroking in Malaysia: Behavioural and perception analysis (Tesis Ph.D tidak diterbitkan). Durham University, UK.

Bhatt, P., \& Sinnakkannu, J. (2008, 13-14 Oktober). Ar-rahnu (Islamic Pawning Broking) opportunities and challenges in Malaysia. Kertas kerja dibentangkan di $6^{\text {th }}$ International Islamic Finance Conference 2008, anjuran Monash University, Kuala Lumpur.

Fatimah Ismail. (1987). Gadaian dan amalan dalam masyarakat Melayu: Satu kajian menurut hukum Islam di Mukim Kurung Hitam, Kuala Nerang, Kedah. Kertas Projek, Fakulti Syariah, Universiti Malaya.

Malaysia. (2003). Akta A1209. Akta Pemegang Pajak Gadai 1972 (Pindaan) 2003. Kuala Lumpur: Percetakan Nasional.

Mohd Rafi Yaacob, Ghazali Ahmad, Mohamed Dahlan Ibrahim, Norwatim Abd Latiff, Noraesyah Saari, Shamsul Khairi Abu Hasan, Norsyeirawani Shari, \& R. Zarinatun Mohd Abdul Kader. (2012). Islamic pawn broking (ar Rahnu): Critical success factor and Application for co-operatives. Diperoleh daripada http://webcache.googleusercontent.com 
Muhammad Saiful Islami Mohd Taher. (2006). Penerimaan pelanggan terhadap skim pajak gadai (al-rahn): Kajian di Kedai ar-Rahnu Bank Rakyat cawangan Alor Setar, Kedah (Tesis sarjana tidak diterbitkan). Jabatan Syariah dan Ekonomi, Universiti Malaya, Kuala Lumpur.

Myers, M. D. (2009). Qualitative research in business and management. London: SAGE Publications.

Nafisah Mohamed, Abdul Ghafar Ismail, \& Selamah Maamor. (2013). Operators. Dlm. Selamah Maamor \& Abdul Ghafar Ismail (Eds.), Ar-Rahnu: Islamic pawnbroking (hlm 163-183). Kuala Lumpur: Dewan Bahasa dan Pustaka.

Nur Azura Sanusi \& Mohamad Shukri Johari. (2006, Ogos 29-30). Prestasi perkhidmatan ar-rahnu: Kajian kes MGIT. Kertas kerja dibentangkan di National Seminar in Islamic Banking and Finance: Islamic Wealth Management, Prospects, Issues and Challenges, Serdang, Selangor.

Portal rasmi fatwa Malaysia. Diperoleh daripada http://www.e-fatwa. gov.my

Safinar Salleh. (2005). Sistem gadaian Islam: Pengamalan dan keberkesanan operasinya di negeri Perlis (Tesis sarjana tidak diterbitkan). Jabatan Fiqh dan Usul, Universiti Malaya, Kuala Lumpur.

Selamah Maamor. (2013). Success story of ar-rahnu customers. Dlm. Selamah Maamor \& Abdul Ghafar Ismail (Eds.), Ar-Rahnu: Islamic pawnbroking (hlm. 303-306). Kuala Lumpur: Dewan Bahasa dan Pustaka.

Selamah Maamor, Abdul Ghafar Ismail, Nur Azura Sanusi, Raziah Md. Tahir, \& Zalina Zainal. (2005). Pawn shop in Malaysia: The effectiveness and expansionary of micro-credit. IRPA: 05-02-070077-EA001.

Skully, M. T. (2005, November 17). Islamic pawnbroking: The Malaysian experience. Kertas kerja dibentangkan di $3^{\text {rd }}$ International Islamic Banking and Finance Conference 2005, anjuran Monash University Malaysia, RHB Bank dan ALDWICH WIPRO, Kuala Lumpur. 
IJMS 21 (2), 111-134 (2014)

\section{Lampiran 1}

Profail Responden dan Institusi Pajak Gadai Islam

\begin{tabular}{lcl}
\hline & Wakil Institusi & \multicolumn{1}{c}{ Jawatan/ Institusi } \\
\hline 1. & A & $\begin{array}{l}\text { Penolong Pengurus Unit Pengurusan ar-Rahnu, } \\
\text { MAIDAM }\end{array}$ \\
2. & B & Akauntan Unit Pengurusan ar-Rahnu, YaPEIM \\
3. & C & $\begin{array}{l}\text { Pegawai Kanan Bank Kerjasama Rakyat Malaysia, } \\
\text { Tanjung Malim, Perak }\end{array}$ \\
\hline
\end{tabular}


IJMS 21 (2), 111-134 (2014)

\section{Lampiran 2}

Soalan Temu Bual Separa Berstruktur dengan Pemegang Pajak Gadai Islam
1. Apakah prinsip-prinsip shariah yang terkandung dalam kontrak ar-rahnu?
2. Adakah terdapat sebarang institusi dalam sejarah Islam yang menjalankan pajak gadai berasaskan prinsip kewangan Islam atau sistem pajak gadai Islam yang dilaksanakan pada masa kini hanyalah sekadar mengislamkan institusi pajak gadai konvensional?

3. Pada pendapat anda, bolehkan sistem pajak gadai Islam mengekalkan perniagaan mereka dengan hanya mengenakan upah simpan yang minimum kepada pelanggan?

4. Adakah skim pajak gadai islam anda mempunyai cadangan untuk menerima barangan lain selain emas sebagai cagaran?

5. Adakah skim pajak gadai islam anda mempunyai cadangan untuk membangunkan peraturan atau akta yang standard dengan institusi-institusi lain yang menawarkan perkhidmatan pajak gadai Islam?

6. Pada pendapat anda, adakah sistem pajak gadai Islam lebih menggalakkan pembiayaan untuk tujuan penggunaan/ perbelanjaan berbanding tujuan pengeluaran/aktiviti produktif? Sekiranya perkara ini berlaku, adakah anda setuju bahawa perkara ini adalah tidak selari dengan prinsip pembiayaan dalam Islam? Atau adakah anda merasakan maslahah perlu diambilkira dalam memahami tujuan pembiayaan penggunaan mereka?

7. Apakah masalah shariah yang diatasi melalui pelaksanaan pajak gadai Islam?

8. Mengapa masyarakat Islam masih menggunakan pajak gadai konvensional walaupun wujud pajak gadai Islam?

9. Adakah terdapat sebarang permintaan terhadap produk pajak gadai Islam di kalangan masyarakat bukan Islam?

10. Sila berikan komen anda tentang bagaimana untuk meningkatkan kepekaan masyarakat terhadap produk ar-rahnu? 